\title{
(2) OPEN ACCESS \\ Educational opportunities for postgraduate medical trainees during the COVID-19 pandemic: deriving value from old, new and emerging ways of learning
}

\author{
Kartik Kumar (10 1,2 Katherine Groom, ${ }^{3}$ Laura Martin, ${ }^{1}$ Georgina K Russell, ${ }^{1}$ \\ Sarah L Elkin ${ }^{1,2}$
}

1 Department of Respiratory Medicine, St Mary's Hospital, Imperial College Healthcare NHS Trust, London, UK ${ }^{2}$ National Heart and Lung Institute, Imperial College London, London, UK ${ }^{3}$ Department of Respiratory Medicine, Hammersmith Hospital, Imperial College Healthcare NHS Trust, London, UK

\section{Correspondence to}

Dr Kartik Kumar, Department of Respiratory Medicine, St Mary's Hospital, Imperial College Healthcare NHS Trust, London W2 1NY, UK ;

kartik.kumar@nhs.net

Received 4 June 2021 Accepted 11 July 2021

Check for updates

(c) Author(s) (or their employer(s)) 2021. Re-use permitted under CC BY-NC. No commercial re-use. See rights and permissions. Published by BMJ.

To cite: Kumar K, Groom K, Martin L, et al.

Postgrad Med J Epub ahead of print: [please include Day Month Year]. doi:10.1136/

postgradmedj-2021-140603

\section{ABSTRACT}

The COVID-19 pandemic has had a significant impact on postgraduate medical training across all specialties. Although some traditional learning opportunities have been curtailed, there have been numerous examples of highly valuable educational experiences that have arisen during this time. Here, from a trainee perspective, we consider the educational merits of the re-emergence of 'firm-based' teams, new online learning opportunities, use of digital technologies and the rise of telephone clinics and new COVID-19 clinical services. As health services continue to recover from surges in COVID-19 cases, it is important to reflect on and recognise the value of these educational experiences so that helpful elements can be retained and embedded into training programmes for the benefit of both trainees and patients.

\section{BACKGROUND}

Formal educational opportunities for postgraduate medical trainees across all specialties have been significantly impacted by the COVID-19 pandemic. ${ }^{1}$ Clinical training days have been cancelled; annual review of competence progression requirements amended; out-of-programme opportunities curtailed or reworked; and clinical rotas reconfigured to prioritise the frontline emergency response. Many trainees have been redeployed from their specialties, ${ }^{2}$ reducing their experience in specialist clinics, attendance at clinical meetings and ability to undertake specialty-specific procedures. However, amidst these challenges have arisen many positive learning experiences and novel ways to access medical training opportunities. ${ }^{3}$ As clinical rotations were temporarily paused in the UK, 'firmbased' teams re-emerged; access to online education erupted with the use of Microsoft Teams and Zoom (Zoom Video Communications); and for those not on the frontline, the ability to participate in telephone clinics, general practitioner (GP) support lines and COVID-19 follow-up clinics provided valuable training opportunities. Here, from a trainee perspective, we consider the merits of these educational experiences, many of which could be adopted long-term and continued in parallel with conventional training opportunities.

\section{THE FIRM}

The understandable need to halt clinical rotations may have been disappointing for some trainees who were due to rotate into a particular specialty, hospital, location or out-of-programme experience. The pandemic has exposed trainees to clinical challenges and responsibilities that they may otherwise never have experienced. Combined with changes in working hours and a disruption in usual social support networks, the importance of maintaining trainee well-being has arguably never been greater. However, a potential benefit of the pause in rotations has been the re-emergence of a firm-based system, a concept otherwise relegated to the past. ${ }^{4}$ In the UK, most Foundation Year trainees rotate posts every 4 months, which some may argue is too brief to develop sufficient clinical experience in a specialty. Spending more time in the same team has potential benefits. Junior doctors may feel more at ease with their senior colleagues, facilitating the ability to ask questions, seek clarification and develop a deeper understanding of the intricacies of a specialty. Moreover, this allows better integration within the wider multidisciplinary team (MDT), creating a more collaborative, inclusive and less hierarchical working environment. Our experience has demonstrated that working relationships are enhanced, morale is boosted and junior doctors feel more supported to enquire and learn. This has had the positive effect of enhancing continuity in and completion of quality improvement projects and audits in conjunction with the MDT. Indeed longer clinical placements have also been valued by undergraduate students participating in apprenticeship-based models of learning during the pandemic. ${ }^{5}$

Those redeployed outside their usual specialties have been able to re-visit and reinforce skills in general medicine, which will be invaluable in helping them to provide holistic, safe care for future patients, regardless of trainees' long-term specialty aspirations. ${ }^{6}$ Redeployment has thus resulted in improved cross-specialty collaboration and a reduction in working in silos. Changes in the structure of hospital teams have meant that there has been closer integration between level 1 and level 2/3 based care, as well as greater opportunities for specialties that may not traditionally work together to form new partnerships, leading to improved learning in both directions. For example, during the recent surge in COVID-19 cases in the UK, our respiratory team was supported by trainees redeployed from the obstetrics and gynaecology team. Our respiratory team also provided regular outreach support to geriatric and surgical wards. 


\section{ONLINE LEARNING}

While traditional face-to-face teaching methods such as grand rounds and training days may have been cancelled or postponed, there has been an emergence in virtual learning and online webinars, providing trainees with ongoing opportunities to learn both as audience members and as presenters; including, for example, in the form of virtual morning reports. ${ }^{7} \mathrm{~A}$ recent review has shown that online learning has been the most frequently used method to mitigate the adverse effects of the pandemic on undergraduate and postgraduate medical education. ${ }^{8}$ Such initiatives can be implemented reasonably rapidly, as demonstrated by the experiences of an institution in Singapore. ${ }^{9}$ Online sessions offer the advantage of being easily accessible, particularly when recorded for trainees to watch at a convenient time. It has also been possible to access online training opportunities from outside one's own institution, encouraging a system of learning from shared experiences across different specialties and hospitals over large geographical regions. ${ }^{10}$

At our institution, regular online webinars on respiratory complications of COVID-19 were set up between respiratory specialists and GPs from local clinical commissioning groups, enabling collaborative learning at the interface of primary and secondary care. A survey from India has shown that healthcare workers value participating in live online teaching sessions that permit direct interaction with speakers and that have a chat function available for questions to be asked in real time. ${ }^{11}$ While there may be potential concerns about the degree of trainee engagement with online teaching, a study from Lebanon found that attendance rates for online sessions were similar to those for face-to-face-teaching. ${ }^{12}$ Guidance has been produced for medical educators on how to prepare effectively for and maximise the utility of online teaching sessions. ${ }^{13}$

Additionally, clinical MDT meetings have moved online, ${ }^{14}$ allowing easier access to specialist shared decision making and trainees to flexibly incorporate attendance at these alongside other clinical commitments. Virtual MDT meetings are on the whole felt to offer an equivalent standard of care to in-person meetings. ${ }^{15}$

\section{DIGITAL TECHNOLOGIES}

Technological and social media platforms have facilitated continued learning during the pandemic. Many COVID-19 themed WhatsApp groups have been formed among clinical teams, enabling trainees to share resources, guidelines, pertinent research articles and clinical experiences. ${ }^{16}$ Similarly Twitter has provided a dynamic forum for signposting to COVID-19 resources and sharing knowledge. ${ }^{17}$ WhatsApp groups between team members have also provided an important support network for trainees. Various digital platforms promoted by the UK National Health Service-for example, Headspace (Headspace), Daylight (Big Health) and Sleepio (Big Health)—have been useful in providing additional well-being support and have complemented face-to-face debriefs and psychological services offered to trainees. In Pakistan, one healthcare institution implemented cognitive behavioural therapy sessions for its medical trainees and set up a hotline that they could call for additional support. ${ }^{18}$ Such resources are important for supporting a good quality education and maintaining a holistic training environment.

Novel implementation of mixed-reality technologies in clinical settings has also been used to maximise educational opportunities. For example, a study has demonstrated the value of clinicians wearing headsets that enable two-way communication with colleagues located remotely, allowing others to see and hear interactions in real time. ${ }^{19}$ This has enabled trainees not present at the bedside to participate in clinical consultations and observe procedures while minimising their potential exposure to COVID-19, thus facilitating ongoing learning in a safe manner. This technology has also been shown to reduce the average time taken for ward rounds, ${ }^{20}$ thereby improving the efficiency of the working day for clinicians.

\section{TELEPHONE CLINICS}

The cancellation of elective investigations, procedures and outpatient services has significantly diminished access to valuable learning opportunities and ways of fulfilling clinical training requirements. Many specialties have set up telephone clinics which have had benefits for both patients and trainees. Our patients with chronic respiratory conditions, a significant proportion of whom were shielding, were particularly concerned about what would happen if they contracted COVID-19 and found their telephone clinic appointments to be supportive and reassuring. From a trainee perspective, holding telephone clinics from home or while self-isolating has encouraged development of strong time management skills and autonomy. The inability to see patients face-to-face has necessitated honing of a novel set of communication skills and reliance on diagnostic acumen, as clinical decisions have needed to be made without the benefit of visual cues, physical examination and access to instant investigations. Additionally, there has been more time to prepare for each patient's appointment without some of the natural interruptions that might be associated with being physically located in a busy outpatient environment.

We scheduled regular virtual meetings with consultant supervisors so that trainees could discuss clinical cases on a daily or weekly basis, providing an opportunity to seek clarification and to undertake formal assessment of clinical competencies. Such telephone clinics provided an invaluable way for training to continue for those trainees who for health or other reasons may not have been able to join the frontline clinical response. Virtual clinics have been successfully implemented across medical and surgical specialties. ${ }^{21}{ }^{22}$ Formal curricula for teaching telemedicine skills to trainees have been well received. ${ }^{23}$

Although there have been many benefits for both patients and trainees, telephone clinics may not be suitable in all cases and there may be potential drawbacks to consider. Technological constraints, including occasional problems with network connectivity, have been challenging at times. For some patients in certain specialties, the inability to perform a clinical examination may be detrimental and delay diagnosis. For other patients, such as those who may have language or hearing difficulties or cognitive impairment, telephone conversations may be challenging or impractical and the services of remote interpreters may not necessarily circumvent all the issues faced.

\section{DEVELOPMENT OF COVID-19 CLINICAL PATHWAYS}

Many educational opportunities have arisen due to innovations and reconfigurations in patient care pathways during the pandemic. In North West London, we as respiratory specialists set up an advice line service for GPs that included respiratory trainees in its staff roster. ${ }^{24}$ The service provided advice regarding COVID19-specific, general respiratory and general internal medicine queries from GPs, enabling trainees to engage with a wide breadth of the respiratory and general internal medicine training curricula. COVID-19 follow-up clinics have allowed trainees to learn firsthand about the short-term, medium-term and long-term sequelae of the disease. All trainees, regardless of grade, have benefited from 
being involved in the provision of care in such clinics, as they have offered experience in a rapidly evolving field of clinical practice while learning how to make clinical decisions in situations where there may be considerable diagnostic uncertainty.

Trainees have also had the opportunity to develop leadership skills by contributing to both the creation of new patient care pathways and the reconfiguration of pre-existing ones. As COVID-19 services were being set up, trainees were able to implement skills in quality improvement and audit in real time as clinical pathways were emerging around them rather than once they had been firmly established, providing novel insights into evolving clinical service design and management. Trainees have also been able to develop valuable research skills by participating in the array of COVID-19 clinical studies taking place across all medical disciplines, spanning both healthcare organisations and academic institutions.

\section{CONCLUSIONS}

Several learning opportunities have therefore arisen and evolved during the COVID-19 pandemic. Most of these could continue to be implemented in the future to bolster the variety of educational experiences available for trainees. While these solutions cannot surmount issues such as providing trainees with experience in specialty-specific interventional procedures, by maximising use of technology and by facilitating trainee involvement in novel ways of continuing clinical practice, it may be possible to mitigate at least partially the challenges that the pandemic imposes on clinical training. It is vital that we recognise the benefits of these new ways of learning so that trainees can continue to progress in their educational development.

\section{Learning points}

- Firm-based clinical team models have provided a training environment that facilitates enhanced learning and camaraderie during the COVID-19 pandemic.

- Online teaching and multidisciplinary team meetings have offered a practical, flexible means by which to continue delivery of medical education.

- Social media platforms have complemented face-to-face strategies to support trainee well-being and disseminate clinical information.

- Telephone clinics have enabled trainees to hone a range of clinical skills, but the limitations of such services should be acknowledged.

- Trainees can benefit from engaging with the design, delivery and reconfiguration of patient care pathways.

\section{Acknowledgements KK is an Imperial 4i Clinician Scientist at Imperial College} London.

Contributors KK and KG are joint first authors and contributed equally. KK and KG drafted the initial manuscript. LM, GKR and SLE critically revised the manuscript for content.

Funding KK is supported by the National Institute for Health Research (NIHR) Imperial Biomedical Research Centre (BRC). KK is also supported by the Lee Family endowment to the Faculty of Medicine at Imperial College London. The funders had no role in the preparation or submission of this manuscript.

Disclaimer The views expressed are those of the authors and not necessarily those of the NIHR or the Department of Health and Social Care.

\section{Competing interests None declared.}

Patient consent for publication Not required.

Provenance and peer review Not commissioned; internally peer reviewed.

Open access This is an open access article distributed in accordance with the Creative Commons Attribution Non Commercial (CC BY-NC 4.0) license, which permits others to distribute, remix, adapt, build upon this work non-commercially, and license their derivative works on different terms, provided the original work is properly cited, appropriate credit is given, any changes made indicated, and the use is non-commercial. See: http://creativecommons.org/licenses/by-nc/4.0/.

\section{ORCID iD}

Kartik Kumar http://orcid.org/0000-0002-3142-5795

\section{REFERENCES}

1 Seifman MA, Fuzzard SK, To H, et al. COVID-19 impact on junior doctor education and training: a scoping review. Postgrad Med J 2021. doi:10.1136/ postgradmedj-2020-139575. [Epub ahead of print: 09 Mar 2021].

2 Payne A, Rahman R, Bullingham R, et al. Redeployment of surgical trainees to intensive care during the COVID-19 pandemic: evaluation of the impact on training and wellbeing. J Surg Educ 2021;78:813-9.

3 Papapanou M, Routsi E, Tsamakis K, et al. Medical education challenges and innovations during COVID-19 pandemic. Postgrad Med J 2021. doi:10.1136/ postgradmedj-2021-140032. [Epub ahead of print: 29 Mar 2021].

4 Rimmer A. The firm: does it hold the answers to teamworking and morale? BMJ 2019:365:14105

5 Stout RC, Roberts S, Maxwell-Scott H, et al. Necessity is the mother of invention: how the COVID-19 pandemic could change medical student placements for the better. Postgrad Med J 2021;97:417-22.

6 Yuen J, Xie F. Medical education during the COVID-19 pandemic: perspectives from UK trainees. Postgrad Med J 2020;96:432-3.

7 Murdock HM, Penner JC, Le S, et al. Virtual morning report during COVID-19: a novel model for case-based teaching conferences. Med Educ 2020;54:851-2.

8 Chasset F, Barral M, Steichen 0, et al. Immediate consequences and solutions used to maintain medical education during the COVID-19 pandemic for residents and medical students: a restricted review. Postgrad Med J 2021. doi:10.1136/ postgradmedj-2021-139755. [Epub ahead of print: 01 Apr 2021].

9 Kanneganti A, Sia C-H, Ashokka B, et al. Continuing medical education during a pandemic: an academic institution's experience. Postgrad Med J 2020;96:384-6.

10 Zuo L, Dillman D, Miller Juvé A. Learning at home during COVID-19: a multiinstitutional virtual learning collaboration. Med Educ 2020;54:664-5.

11 Rathod V, Agrawal T, Sahu D. Will webinars prove to be an effective teaching medium post-pandemic? Postgrad Med J 2021;13. doi:10.1136/postgradmedj-2021-140223. [Epub ahead of print: 13 May 2021].

12 Saab B, Ishak H, Fathallah El Mofti M. Educational changes during the COVID-19 pandemic: a response from Lebanon. Postgrad Med J 2020. doi:10.1136/ postgradmedj-2020-139179. [Epub ahead of print: 12 Nov 2020].

13 Hennus MP, van Dam M. A standard operating procedure for developing and hosting a webinar for healthcare professionals new to online teaching. Postgrad Med J 2021. doi:10.1136/postgradmedj-2020-138767. [Epub ahead of print: 10 Mar 2021].

14 Rajasekaran RB, Whitwell D, Cosker TDA, et al. Will virtual multidisciplinary team meetings become the norm for musculoskeletal oncology care following the COVID-19 pandemic? - experience from a tertiary sarcoma centre. BMC Musculoskelet Disord 2021;22:18

15 Sidpra J, Chhabda S, Gaier C, et al. Virtual multidisciplinary team meetings in the age of COVID-19: an effective and pragmatic alternative. Quant Imaging Med Surg 2020;10:1204-7.

16 Laurentino Lima D, Nogueira Cordeiro Laurentino Lima R, Benevenuto D, et al. Survey of social media use for surgical education during Covid-19. JSLS 2020;24:e2020.00072.

17 Rashid MA, Yip SWL, Gill DArfeen Z, Sharon WLY, et al. Sharing is caring: an analysis of \#FOAMed Twitter posts during the COVID-19 pandemic. Postgrad Med J 2020 doi:10.1136/postgradmedj-2020-139267. [Epub ahead of print: 14 Dec 2020].

18 Khan MR, Samad Z, Haider AH. Supporting front-line postgraduate medical trainees during the COVID-19 pandemic: a checklist for organisations. Postgrad Med J. [Epub ahead of print: 09 Feb 2021]. doi:10.1136/postgradmedj-2020-139441

19 Martin G, Koizia L, Kooner A, et al. Use of the HoloLens2 mixed reality Headset for protecting health care workers during the COVID-19 pandemic: prospective, observational evaluation. J Med Internet Res 2020;22:e21486.

20 Levy JB, Kong E, Johnson N, et al. The mixed reality medical ward round with the MS HoloLens 2: innovation in reducing COVID-19 transmission and PPE usage. Future Healthc J 2021:8:e127-30.

21 Chiu C-Y, Sarwal A, Jawed M, et al. Telemedicine experience of NYC internal medicine residents during COVID-19 pandemic. PLoS One 2021;16:e0246762.

22 Westley S, Creasy H, Shah R, et al. Letter to the editor: productively protecting a cohort of vulnerable plastic surgery trainees in the COVID-19 pandemic in a new virtual trauma clinic. J Plast Reconstr Aesthet Surg 2020:73:1357-404.

23 Savage DJ, Gutierrez O, Montané BE. Implementing a telemedicine curriculum for internal medicine residents during a pandemic: the Cleveland Clinic experience. Postgrad Med J. [Epub ahead of print: 10 Mar 2021].

24 Kumar K, Mak V, Groom K, et al. Respiratory specialists working in different ways: development of a GP Hotline and respiratory support service during the COVID-19 pandemic. Future Healthc J 2020;7:e88-92. 